\title{
21st Century Business Language
}

\author{
Naila Gasimova, Farida Huseynova
}

Department of Foreign Languages, Azerbaijan State Oil and Industry University

\begin{abstract}
Every business letter is written to a purpose and has its own special aim. One of the features of this article is to show how the various letters set out to achieve their aims. The article can be of special help to those who are in business and use commercial correspondence. More and more of our work today is undertaken through writing rather than in person or on the phone. As we are writing so much more these days, we depend on our writing skills to influence, persuade, encourage, collaborate, and to lead.

Yesterday's writing is passive and wordy, and it sounds really dull. It puts a distance between you and the reader. Today's writing sounds more conversational. It's clear and transparent. The personal context makes it more positive and interesting.

We connect with the world today largely through email, websites, bllogs, texting and social media. When connecting through these channels we have only bare facts, without voice and body language. That's why it make sense to use writing that's as close as possible to spoken language and to make a greater connection with your reader.
\end{abstract}

Keywords- appropriate language, business correspondence, plain English, redundant expressions, relationships, strategy of success.

\section{INTRODUCTION}

In the middle of the 20th century, business was conducted on a much more impassive, formal way than it is today. Face-to-face meetings were very formal and aloof. Similarly, the writing that evolved then became very formal, using long-winded, overbearing language. Big words and many redundant expressions to add padding to the sentences were used because writers thought they would impress their readers. They used extensively passive voice, putting a distance between the writer and the reader.

Nowadays business is conducted in a very informal way. It is used a natural, more relaxed, friendly language rather than unnatural, formal language that was used several decades ago.

We use active voice to get to the point quicker, but we still take care to be tactful. The aim in business in general is to develop relationships first, and this is done through connecting well and using appropriate language.

Most readers are busy, impatient and have short attention spans. So it can be said that short messages are best.
Double your chances of getting a message read by cutting your message by half.

\section{SETTING GOALS}

1. Some of the key reasons why we need to relax our language in written communications:

- To establish relationships.People get an impression of us from the first email they receive, so it's important to make a connection by using appropriate words and phrases. For example, 'We spoke' ot 'As spoken' will not have the same effect on our reader as 'Thanks for your call' or 'It was great to speak to you'.

- To communicate our ideas precisely. Using unsuitable or incorrect expressions, or a longwinded writing style, will not give the reader the right meaning or the right impression. It will only lead to misunderstandings, confusion and lengthy correspondence to clarify.

- To convey a good impression. Clear, concise, accurate language will give an impression of efficiency, and will fill the reader with confidence. Careless or inaccurate expressions will do the opposite. Readers may question if such carelessness will extend to other business dealings too.

In this article we will look at the words we use to communicate, and how they are put together, so that we achieve all these aims.

Good writing is like any other endeavour. The more we put into it, the more we will get back.

\section{Six deadly sins of today's business writing}

Here are some of the major problems in all types of business correspondence.

\subsection{Redundant expressions}

Expressions like 'Please be informed', 'Kindly be advised', 'I would like to bring to your attention', and 'I am writing to advise you' should have been regulated to the recycle bin way before the turn of the new millennium. Today's writing is still full of old expressions like these, which are simply redundant.

Instead of 'Please be advised that our next meeting will be held on Tuesday 11 May' it's better to write 'Our next meeting will be held on Tuesday 11 May.' 
Instead of 'Kindly be informed that the fire alarms will be tested at 9 am tomorrow' it's better to say 'The fire alarms will be tested at 9 am tomorrow.'

Instead of 'I am writing to let you know that Mr John Lim is no longer with our company' It's better to say 'Mr John Lim is no longer with our company.'

Sometimes we think we have to use phrases like 'Please be informed' because we are more polite. But we can still be courteous without using these passive, stuffy phrases.

\subsection{Long-winded words and phrases}

Our ancestors used to believe that big words and flowery sentences would impress readers. Today, such writing will only confuse or frustrate readers. Instead of 'I sgould be very grateful, simply say 'Please'. It's better to use short words like buy, try, start and end instead of purchase, endeavour, commence and terminate.The aim should be short words, simple expressions and short sentences in short paragraphs that are clear and concise.

\subsection{Passive voice}

Our ancestors used passive voice because they didn't want to show who was responsible for anything. Passive voice also put a distance between the writer and the reader, which is what the writer wanted in those days. Today's business writing should use active voice, which is more focused, more personalised and much more interesting and clear.

Instead of 'Arrangements have been made for a repeat order to be despatched to youimmediately' it's better to use 'I have arranged for a repeat order to be sent to you today'

Instead of 'The cause of your complaint has been investigated' it's better to write 'I have looked into this matter.'

Passive voice puts a distance between you and your reader. Active voice gives your writing a focus, and is much more personal and natural.

\subsection{Yesterday's language}

It's a very common error to use old-fashioned writing in modern emails.

The following stuffy, old-fashioned phrases were used decades ago and they have no place in today's modern writing:

We refer to your letter of 21 st October .......

The above-mentioned goods will be despatched to you today.

Please see the below-mentioned list of items we have in stock.

Your email of this morning refers........

As spoken this morning..........

As per our telecon..

I kindly request your approval.

Appreciate if you could help to process this claim at your earliest.

We will issue the letter to your good self early next week. www.ijels.com
Could I please request your kind assistance in filling out the below survey for us.

Should you require any further clarification please do not hesitate to contact me.

These phrases are not useful nowadays. We should definitely avoid old-fashioned writing.

Today we should write as though we are having a conversation. If you put some thought and personality and some feeling into your wrtiting, this will ultimately lead to developing great relationships. Instead of phrases given above write the following ones:

Thank you for your letter dated 21 October.

These goods will be sent to you today.

These are the items we have in stock.

Thanks for your email.

Thank you for your call this morning.

It was good to speak to you today.

I hope to receive your approval.

Please process this claim soon.

We will send you the letter early next week.

I hope you will take a few minutes to complete this survey for us.

Please give a call if you have any questions.

Imagine the reader is sitting in front of you!

\subsection{Commas instead of full stops}

One of the most common challenges in business writing today is getting commas and full stops in the right place. One can see commas where there really be full stops. The thing is, when you put a comma (where it really should be a full stop), we 'll read along the sentence, then after the comma and we'll figure out it just doesn't make sense, so we have to reread from the beginning again to try to make sense of your sentence. This is all taking up too much of the reader's time.

Here are the main rules for the comma:

- Use a comma to separate words or phrases in a list

Azerbaijan consists of the following administrative entities: one autonomous republic (Nakhchivan), 66 districts, 70 towns, 13 urban districts, 239 urban type settlements and 4,279 rural settlements.

Writing well takes time, effort and a lot of hard work.

- Use a comma to separate adjectives qualifying the same noun

The ethnic, aesthetic and artistic creativity of a people finds expression in their garments, embroidery, weaving and knitting.

I enjoy the warm, humid climate in Singapore.

- Use a comma to separate two clauses that are joined by a co-ordinating conjunction (like but, or, yet, so, for, and or nor)

The menu for Novruz evening may vary, but one obligatory dish is plov(pilaff).

Page | 27 
John has the necessary qualifications, but Dave has more experiences.

- Use commas to create parentheses, where something is inserted that either expands on the main sentence or qualifies part of it.

Ninety per cent of the carpets, especially the flatwoven ones, are original Azerbaijani carpets.

I need Mark, and possibly Doreen as well, to help with this project.

- Use a comma to separate phrases and clauses to make your message easier to read.

Caucasian pistols and guns, despite the simple technology of their manufacture, were of exellent constructional design and high-firing power.

Although I agree with the points you mention, I would like clarification on various issues.

One thing is for sure- commas should not be overused. In today's business writing we should keep sentences short and cut out non-essential commas.

You know that a comma represents a short pause. When reading any written messages, don't just see words on paper- imagine you are reading the sentences out loud, as though you are speaking to your audience. This will help you to place the comma and full stops correctly.

\subsection{Thank you and regards}

Put some life into your business writing by using a natural, relaxed, friendly style, as though you are having a conversatio. Instead of using yesterday's jargon, use a style that is proactive, stimulating and interesting-writing that reflects your personality.

If you have been courteous throughout your communication there should be no need to keep saying 'Thank you' over and over again just because someone reads your letter or email. If you have something to thank the reader for, you might consider ending with 'Thank you for you help', 'Thank you for your patience', 'thank you for your understanding' or something similar.

As for 'Regards', I' suggest just dropping this. We see several alternatives too, like 'Best regards', 'Warm regards'. To me they are rather cold. I strongly believe that putting our personality into our writing throughout our message is better, and then just put your name at the end. When appropriate we could close with a little nicety like 'See you soon' or 'Have a great weekend',or ' Good luck with the meeting'. Or how about 'Many thanks'? Follow this final remark with your name and it closes your message in a very friendly, relationship-building way.

\section{METHODS OF SOLUTION}

\section{Several ideas to brilliant business writing}

An informal online culture has evolved over the years, but there have never been strict guidelines to common standards and expectations among years.Consequently, www.ijels.com miscommunication has been rampant and time has been wasted.

- One thing is for sure-things are often written in an email message would not be written in a business letter.

In all messages it is essential to be able to transfer thoughts and ideas from yourself to another One thing is for sure One thing is for sure One thing is for sure One thing is for sure One thing is for sure One thing is for sure person. To do this effectively, you must put yourself in the place of the reader and imagine how they will accept what is written in the tone used. You must anticipate the reader's needs, wishes, interests, problems, and consider the best way of dealing with the specific situation.

- We have follow the art of plain English.

Plain English is not only faster to write and read. It also enables us to get your message across more often, more easily, and in a friendly way. What's the secret of composing good business messages in plain English?

If you want to be understood, you must use simple language, and put your message across in a natural way, using a courteous style, and using language you would use if you are speaking.

- It is of great importance to avoid too many sentences beginning with the same word,

like 'I', 'We' or 'Please'. You need to be creative and restructive. Just because you have two sentences beginning with 'Please', it's not an excuse for you to change one to the outdated 'Kindly'.

- Get the tone right!

Tone means the emotional context of our messages, the degree of formality or informality we use in our writings, and the attitude towards the topic and the recipient.

We have to put our message over as concisely as possible while still being courteous, clear, concise and correct.

The tone we use in our internal correspondence will be a reflection of the following issues:

- our status

- the reader's status

- our relationship with the reader

- the message we want to give

let's consider some examples written in inappropriate tone, and how they can be improved:

1. Instead of

I have looked through your report and I am totally confused. Please see me urgently to clarify.

We have to say

I have some questions about your report. Please come and see me to discuss.

2. Instead of

Have your report on my desk by 8 am tomorrow at the latest.

We have to say

Please let me have your report by 8 am tomorrow.

Page | 28 
3. Instead of

The new price structure you suggest is totally impractical. We have to say

I have some suggestions about the new price structure you suggested.

4. Instead of

Our phone bills are enourmously high. Please tell your staff to stop making so many personal calls.

We have to say

Our phone bills have increased considerably. Please ask your staff to avoid non-urgent personal calls during working hours.

Never be unsympathetic, condescending or rude. Always be sincere and clear.

One big tip for positive writing is to avoid using 'but' wherever possible. It generally erases everything positive that came before it. The reader will just focus on the negative. Look at the following examples and compare them.

This model is very popular but it only does 35 miles per gallon.

This model is very popular and it does 35 miles per gallon.

The second example is without 'but'. Do you see how much more positive the second sentence sounds?

There are also positive and negative words. Take a look at these examples of such words.

Positive words: benefit, congratulations, delighted, generous, glad, proven, sale, save, convenient, qualified, excellent, satisfactory, thank you, of course, pleasure, garantee.

Negative words: impossible, damaged, unable to, mistake, problem, loss, delay, failure, trouble, cannot, complaint, inconvenient, difficulty, regret, neglected, except.

Using positive words and positive phrases will enhance the tone and improve the effectiveness of our writing.

\section{CONCLUSION}

Presenting yourself as an optimist is a well-proven strategy of success. This works in writing greatly. First of all let the reader know what you can do and will do, rather than what you can't and won't do.

Before signing or sending any written message ask your self these questions:

- Have you used simple words and simple expressions?

- Have you avoided wordiness while remembering the need for courtesy?

- Is your tone conversational and natural, as if you were speaking?

- Have you used active voice instead of passive?

- Have you used the right tone for the issue you are writing about and for the person you are addressing?
- Have you included all the essential information?

- Have you used any old-fashioned language or jargon that should be updated?

- Is your language brief but still courteous

All these questions, on the basis of which this article is written, are important when conducting business correspondence.

The main rules for written communication are reinforced constantly throughout this article.

The article is useful for those who would like to create a great writing style.

\section{REFERENCES}

[1] Jay, Ros (2003). How to Write Proposals and Reports that Get Results. United Kingdom.

[2] A Plain English Handbook. (1998). U.S. Securities and Exchange Commission. How to Create Clear SEC Disclosure Documents. Washington, D.C.,pp. 17-36.

[3] Krashen, S. (2004). The power of reading. Portsmouth, NH: Heinemann and Santa Barbara: Libraries Unlimited (second edition).

[4] Kroll, B.M. (1981). Developmental Relationship between Speaking and Writing. In B. Kroll \& R. Vann, (Eds). Exploring Speaking-writing Relationships: Connections and Contrasts. Illinois: National Council of Teachers of English, pp. 32-54.

[5] Lee, S. (2003). Teaching EFL Writing in the University: Related Issues, Insights, and Implications. Journal of National Taipei Teachers College, 16(1), 111-136.

[6] Lin, O. and Maarof, M. (2013). Collaborative Writing in Summary Writing: Student Perceptions and Problems, Procedia - Social and Behavioral Sciences, 2013

[7] Lundstrom, K. and Baker, W. (2009). To give is better than to receive: The benefits of peer review to the reviewer's own writing, Journal of Second Language Writing 18, 30-43, 2008.

[8] McMullen, M. (2009). Using language learning strategies to improve the writing skills of Saudi EFL students: Will it really work?

[9] Mercer, N. and Dawes, L. (2008). The value of exploratory talk. In N. Mercer and S. Hodgkinson (Eds.), Exploring talk in school, pp. 55-71, London, UK: Sage.

[10] Nunan, D. (1999). Second Langue Teaching and Learning. Boston, Mass.: Heinle and Heinle.

[11]Rajab, H. (2013). Developing Speaking and Writing Skills of L1 Arabic EFL Learners through Teaching of IPA Phonetic Codes. Theory and Practice in Language Studies. 
[12] Silva, T. (1993). Toward an understanding of the distinct nature of L2 writing: The ESL research and its implications. TESOL Quarterly

[13] Spack, R. (1998). Guidelines: A cross-cultural reading/writing text. $2 \mathrm{~d}$ ed. Cambridge: Cambridge University Press.

[14] Storch, N. (2005). Collaborative writing: Product, process, and students' reflections. 